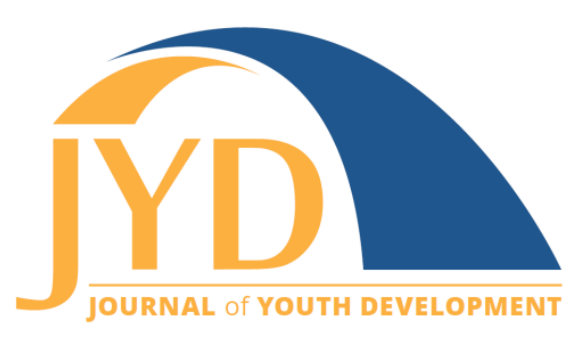

http://jyd. pitt. edu/ | Vol. 14 Issue 3 DOI 10.5195/jyd.2019.769 | ISSN 2325-4017 (online)

\title{
Psychological Engagement and Behavioral Activity Participation as Predictors of Positive Youth Development
}

\author{
Heather L. Ramey \\ Humber Institute of Technology \& Advanced Learning, Brock University, Centre of Excellence for Youth Engagement \\ heather.ramey@humber.ca
}

Heather L. Lawford

Bishop's University, Brock University, Centre of Excellence for Youth Engagement

hlawford@ubishops.ca

Linda Rose-Krasnor

Brock University

linda.rose-krasnor@brocku.ca

\begin{abstract}
Youth's structured (e.g., sports) and unstructured (e.g., socializing) activities are key contexts for positive development. Both behavioral participation (e.g., frequency) and elements of psychological engagement (e.g., enjoyment, challenge) in programs and activities have been linked to components of youth development. We tested a model in which both psychological engagement and behavioral participation in activities predicted overall positive youth development in older adolescent and emerging adult samples (Sample 1, $\mathrm{n}=235$, mean age $=18.7$ years, $\mathrm{SD}=1.4$ years, $67.7 \%$ female; Sample 2, $\mathrm{n}=186$, mean age $=20.0$ years, $\mathrm{SD}=2.1$ years, $68.8 \%$ female). In the first known study to include behavioral participation and multidimensional psychological engagement in predicting the Five Cs of positive youth development, we found that greater psychological engagement, but not behavioral participation, was related to higher positive youth development across samples and different activity types. Findings suggest that promoting youth's psychological engagement in programs and other activities, rather than just their physical presence, may be advantageous for strengthening positive youth development.
\end{abstract}

Key words: psychological engagement, activity participation, positive youth development, emerging adults, youth engagement

(c) $\mathrm{EY}_{\mathrm{EY}}$ New articles in this journal are licensed under a Creative Commons Attribution 4.0 License. This journal is published by the University Library System, University of Pittsburgh and is cosponsored by the University of Pittsburgh Press. The Journal of Youth Development is the official peer-reviewed publication of the National Association of Extension 4-H Agents and the National AfterSchool Association. 


\section{Psychological Engagement and PYD}

\section{Introduction}

Positive youth development (PYD) frameworks focus on supporting youth in realizing their full developmental potential (e.g., Lerner, Lerner, Bowers, \& Geldhof, 2015), often in the context of youth programs (Arnold \& Silliman, 2018). The most prominent definition of PYD involves the Five Cs: competence, caring, social connections, confidence, and moral character (Lerner et al., 2015). Numerous studies have provided evidence linking participation in programs and other activities (e.g., sports teams, clubs) in adolescence and emerging adulthood to single elements of youth's positive development, including better health, fewer externalizing problems, and completing more years of education (e.g., Denault \& Poulin, 2017). Studies of program and activity participation have typically relied on behavioral indicators, such as how often or how long a youth has participated (Vandell, Larson, Mahoney, \& Watts, 2015). Youth's psychological engagement (e.g., enjoyment, challenge) in their activities has received less attention. Some recent studies, however, have found that elements of psychological engagement have been more important in predicting positive outcomes than the frequency or duration of young people's participation (e.g., Forgeard \& Benson, 2017). In addition, based on findings that most adolescents are under-prepared for a successful transition into adulthood, researchers have suggested that programs should do more to offer opportunities for PYD with older youth (Scales et al., 2016). In the current study, we built on past findings, testing multiple dimensions of psychological engagement and behavioral participation as potential predictors of youth's overall PYD, in late adolescence and emerging adulthood.

\section{Psychological Engagement and Behavioral Participation}

Activity participation is an important predictor of positive development, with research typically focusing on youth programs and other structured activities (Vandell et al., 2015). Current measures of activity participation are usually behavioral, assessing how often people participate (frequency/intensity) or the length of their involvement (duration; Vandell et al., 2015). These behavioral measures have been related to different developmental indicators, such as physical health, years of education, depressive symptoms, and civic engagement (Denault \& Poulin, 2017; Viau, Denault, \& Poulin, 2015).

Recently, research has increasingly pointed to the importance of psychological engagement, beyond mere presence, in an activity (Ramey et al., 2015). Past theory and research suggest that subjective experiences of flow, meaningfulness, and interest in activities are important aspects of youth's positive development (e.g., Csikszentmihalyi, 1999; Hunter \& 


\section{Psychological Engagement and PYD}

Csikszentmihalyi, 2003). Relatedly, psychological engagement in activities has been considered a multidimensional construct, comprising cognitive (e.g., focus), affective (e.g., enjoyment), and relational/spiritual (e.g., relatedness to others) factors (Bohnert, Fredricks, \& Randall, 2010; Ramey, Lawford, \& Rose-Krasnor, 2017).

It is likely that both psychological engagement and behavioral participation are theoretically necessary to capture the developmental opportunities offered by activities. The frequency or duration of youth's attendance is unlikely to influence outcomes if youth are simply "going through the motions" (Bohnert et al., 2010, p. 594) but consistent attendance may enhance any existing program outcomes. Similarly, it is possible that youth could demonstrate positive emotion and effort in their activity, but not participate enough to accrue developmental benefits (Bohnert et al., 2010).

Empirically, the few studies that have included measures of both psychological engagement and behavioral participation in structured activities have found these dimensions differentially predicted youth functioning. Elements of adolescents' psychological engagement (e.g., enjoyment) have been associated with suicide-predictive risk (Ramey et al., 2010), community belonging and social responsibility (McGuire \& Gamble, 2006), and self-esteem (Adachi \& Willoughby, 2014) in young people, over and above behavioral participation. Forgeard and Benson (2017) found that while intensity did not predict well-being in a sample of older adolescents and emerging adults, duration and aspects of psychological engagement (enjoyment and interest) were related to well-being. Champine and Johnson (2017) found that cognitive, emotional, and behavioral engagement predicted different elements of youth's character development, in a sample of older children and early adolescents in the Scoutreach program. Thus, although behavioral and psychological dimensions have been separately measured and connected to PYD elements, evidence of a link between overall measures of psychological engagement and PYD is lacking. Linking psychological engagement and PYD at a global level would provide a more comprehensive picture of how well psychological engagement predicts youth's overall functioning.

Activity participation might hold particular relevance in late adolescence and emerging adulthood. In a study of trajectories of participation across adolescence and into emerging adulthood, Denault and Poulin (2017) found that most young people's activity participation decreased, despite the apparent benefits of maintaining participation in programs and other activities. They found that greater activity participation beyond high school was related to lower externalizing problems and greater educational attainment. More specifically, Busseri et al. 


\section{Psychological Engagement and PYD}

(2011) found that greater breadth and frequency of participation across the transition from high school to postsecondary education was related to positive adjustment. From a PYD perspective, activity participation might provide opportunities for youth to develop competencies and assets that mark healthy development in these age groups, and might buffer young people from risk during the transition into postsecondary education (Busseri et al., 2011; Geldhof, Gestsdottir et al., 2015).

\section{PYD and Activity Engagement}

Theoretically, PYD develops when youth's strengths align with opportunities provided by their context (Lerner et al., 2015). Psychological engagement is a reflection of youth's individual, subjective experiences while participating, and therefore might reflect a good "alignment" or "fit" between the activity context and a young person's strengths or needs. Similarly, youth may be more likely to be physically present when activities provide necessary resources and opportunities.

Activity engagement research has extended from middle childhood and into the third decade of life, an age range in which PYD also applies (Lerner, 2018). Previously, researchers have found that different profiles of adolescents' sports participation and more frequent participation in a greater variety of activities were associated with overall PYD into late adolescence (Agans et al., 2014; Agans \& Geldhof, 2012). Mueller et al. (2011), however, examined participation in development programs in youth from early to mid-adolescence, and found that frequency of participation was not directly related to the Five Cs of PYD. The inconsistency of these findings indicate the need to disentangle the independent and relative potential contributions of both psychological and behavioral indicators of participation in predicting PYD.

Activity participation researchers have primarily focused on structured programs and activities, defined by a regular meeting time, adult or more knowledgeable leaders, and a predetermined curriculum (Vandell et al., 2015). Sports may be the most frequently investigated activity type, in relation to PYD (e.g., Holt, 2016). Sports may also offer youth a unique combination of features, including competition, physical activity, skill building, and peer status and, in the case of team sports, opportunities for team building and positive relationships (e.g., Hansen, Skorupski, \& Arrington, 2010). In a qualitative study of activity involvement, adolescents reported sports were unique in providing enjoyable experiences of challenge, while promoting feelings of competence, compared to structured non-sport and unstructured activities (Gadbois, Bowker, Rose-Krasnor, \& Findlay, 2019). Research by Denault and Poulin (2016) indicated that 


\section{Psychological Engagement and PYD}

team sports were associated with more positive experiences than participation in other structured activity types. Relatedly, Zarrett et al. (2009) found that a profile of participation in both sports and other activities was most associated with PYD among their fifth through seventh grade participants. Other research that has examined different types of structured activities and PYD in adolescence has not clearly indicated benefits of sports versus non-sport activities (e.g., Agans et al., 2014; Forneris, Camiré, \& Williamson, 2014). Given past attention to these activity types, in the current study we planned to determine whether our final model differed for sports and non-sport activities.

Larson (2000) described structured activities, alone, as unique contexts of development, arguing that they involved a combination of both high attention and high intrinsic motivation. Larson, Hansen and Moneta (2006) examined developmental experiences in organized activities compared with youth participation in academic classes, unstructured time with friends, and employment. Their findings suggested that sports, arts, community activities, service, and faithbased activities tended to provide better developmental experiences than school or work. Unexpectedly, however, and inconsistent with their own prior findings (Hansen, Larson, \& Dworkin, 2003), Larson et al. (2006) found that organized activities did not consistently provide better developmental experiences than hanging out with friends. The adolescents interviewed by Gadbois et al. (2019) similarly reported that unstructured activities provided a rich array of positive developmental experiences (e.g., socializing, learning new skills), which were similar to those reported for structured activities, such as sports and clubs. These findings suggest the need to examine these different developmental contexts separately. Indeed, scholars, such as Hunter and Csikszentmihalyi (2003) have researched a broader range of activities, including unstructured contexts such as socialization with friends, in their studies of subjective experiences within activity settings. We similarly have included unstructured activities including socializing with friends and family, games, hobbies and media time as activities of interest. These unstructured activities were of particular importance given the amount of time youth spend in these activities, particularly during emerging adulthood, and their potential developmental importance (e.g., Hunter \& Csikszentmihalyi, 2003; Larson, 2000). In line with our planned analysis of sport and non-sport activities, we similarly tested the fit of our potential model across structured (e.g., sports, clubs) and unstructured (e.g., socializing, hobbies) activities. 


\section{Psychological Engagement and PYD}

\section{The Current Study}

In sum, past research has linked aspects of youth's psychological engagement and behavioral participation in activities, and aspects of PYD. In the current study, we tested for links between youth's overall psychological engagement and behavioral participation, separately, and youth's overall PYD in older adolescence and emerging adulthood. This provided a more holistic assessment of these psychological engagement and PYD than typical of past research. We also tested the importance of young people's psychological engagement in activities, over and above their physical presence. Following Scales et al. (2016), programs and activity leaders may need to pay particular attention to PYD in these age groups, as young people transition into postsecondary and into adulthood.

We expected that both behavioral participation (duration, frequency) and psychological engagement (cognitive, affective, relational) would positively and uniquely predict PYD, in samples of older adolescents and emerging adults. However, we hypothesized that psychological engagement would be a stronger predictor of PYD than would behavioral participation. This hypothesis was based on past research findings that aspects of psychological engagement predicted youth well-being and positive development, over and above aspects of behavioral participation (e.g., Forgeard \& Benson, 2017). We also tested the model across activity type (sports versus non-sports and unstructured versus structured) but did not expect any activity-related differences in the relation between engagement and PYD. Although Larson (2000) described structured activities as unique, he argued that this was because they were the most likely context for high psychological engagement. It therefore follows that although different program and activity contexts might be more or less likely to foster high psychological engagement, it should be psychological engagement that is key, rather than the activity type itself. This study, therefore, adds to current research by testing the role of youth's psychological engagement in predicting PYD at an important stage of youth development and across activity types. This study offered the possibility to add to practitioners' and other adults' knowledge of a potentially important factor in youth's program participation and across other settings of youth's lives.

\section{Method}

\section{Participants and Procedure}

We recruited two distinct samples for a longitudinal study of positive development. Ethical approval was granted by the Research Ethics Boards at both institutions. Participants in Sample 


\section{Psychological Engagement and PYD}

1 were 235 first-year students attending a junior college in Quebec, Canada (mean age = 18.7 years; $S D=1.4$ years; range $17-24 ; 67.7 \%$ female). They were recruited through visits to a common area on campus over a 2-month period during spring 2014. They were invited to complete paper surveys. Participants most frequently identified as White (81\%), Black (3\%), Asian (3\%), and mixed origin (5\%). The modal grade average (for $42 \%$ of participants) was between $80 \%$ and $89 \%$. Participants most commonly reported mothers as having completed "some university or college" (33\%) and least commonly as "some high school" (7\%).

Participants in Sample 2 were 186 college students in social and community services programs in Ontario, Canada (mean age $=20.0$ years; $S D=2.1$ years; range $17-29 ; 68.8 \%$ female). Students were recruited through visits to first-year classes in January 2016. They were invited to complete paper surveys. Most were students in criminal justice degree (36.6\%) and diploma (33.9\%), and child and youth care degree (12.9\%) and diploma (15.1\%) programs. Degree programs were 4 years in duration, and diploma programs were 2 or 3 years in duration. Participants most frequently identified as White (44\%), Black (21\%), Asian (19\%), Latin American (6\%), and mixed origin (5\%). The most common grade average ( $40 \%$ of participants) was between $70 \%$ and $79 \%$. Participants most commonly reported mothers as having completed university or college (31\%), and least commonly as completed professional or graduate school (8\%).

There were some demographic differences between the samples. The college sample was significantly older than the junior college sample, $t(419)=-10.58, p<.001$, and reported higher maternal education, $t(419)=2.80, p=.005$. There was no significant difference in gender makeup.

\section{Measures}

\section{Demographics}

Age, gender, average grades, maternal education, and ethnicity each were assessed with single-item measures. Responses for maternal education could range from 1 (some high school) to 5 (professional degree or graduate school).

\section{Psychological Engagement}

Behavioral participation, psychological engagement, and activity type were assessed with the snapshot survey of engagement (Busseri, Rose-Krasnor, \& Centre of Excellence for Youth 


\section{Psychological Engagement and PYD}

Engagement, 2009; Ramey et al., 2015). The instructions first stated the following: "An activity can be anything that you participate in that has a focus outside of yourself. Some examples are spending time with friends and family, playing music in a band, being on a sports team, or volunteering in the community, but there are many other types of activities" (see Pancer, RoseKrasnor, \& Loiselle, 2002). Participants were then asked to identify and report on their most important activity. Psychological engagement was measured with nine items, comprising cognitive (e.g., focus); affective (e.g., enjoyment), and relational/spiritual engagement (e.g., connections to others or to something greater than the self). Responses could range from 1 (not at all) to 5 (completely). Composites of each dimension were created for the purposes of reporting correlations.

\section{Behavioral Activity Participation}

Participants were asked for the frequency and duration of their participation in their most important activity. Responses could range from 1 (done it just once) to 6 (several days a week) and from 1 (just started doing it) to 6 (more than 5 years).

\section{Activity Type}

Activity descriptions were coded into the following categories, following a method developed in our past work (Ramey et al., 2010): sports/physical activity (Sample 1, 48.9\%; Sample 2, $41.0 \%$ ); socializing with friends or family (Sample 1, 17.6\%; Sample 2, 20.8\%); music/arts (Sample 1, 16.3\%; Sample 2, 8.7\%); community or school clubs (Sample 1, 4.3\%; Sample 2, 9.3\%); volunteering (Sample 1, 2.6\%; Sample 2, 5.5\%); education/employment (Sample 1, 3.9\%; Sample 2, 6.6\%); and games/hobbies/media (Sample 1, 6.4\%; Sample 2, 8.2\%). Organized activities that met regularly with an adult leader were considered structured, while unstructured activities included socializing and games/hobbies/media.

\section{Positive Youth Development}

The Five Cs of PYD were measured with 14 items from the late-adolescence version of the PYD Very Short Form (PYD-VSF; Geldhof et al., 2014). As we were testing an overall PYD measure, rather than individual $\mathrm{Cs}$, some items from the measure were not included (Geldhof et al., n.d.; Geldhof, Bowers et al., 2015). Items represented all Five Cs (caring, 3 items, e.g., "When I see another person who is hurt or upset, I feel sorry for them"; confidence, 3 items, e.g., "All in all, I am glad I am me"; and connection, 4 items, e.g., "In my family, I feel useful and important"). 


\section{Psychological Engagement and PYD}

Questions on some other items are structured to reflect the degree to which participants identify with people along a spectrum, or how important each of the following is to their lives: character, three items, e.g., "accepting responsibility for my actions when I make a mistake or get in trouble"; competence, two items: "some people do very well at their class work and other people don't do very well at their class work" and average grades, following Erentaite and Raižienè (2015). Scoring for some items was transformed so that all were consistent with a range of 1 to 5, with higher scores indicating greater PYD.

\section{Analysis}

Some participants (Sample 1, 0.9\%; Sample 2, 1.8\%) did not complete all survey questions. Missing data were imputed using the EM algorithm in SPSS (Schafer \& Graham, 2002).

The main analysis was conducted with structural equation modeling (SEM) using the Amos program, on the combined sample. We assessed a measurement model that included the three first-order psychological engagement variables loaded onto a latent psychological engagement variable, and the Five Cs of PYD loaded onto a latent PYD factor. Testing this model across the two samples included several preliminary steps, typically known as invariance testing, to ensure that different elements of the model fit consistently across both groups of youth (Cheung \& Rensvold, 2002; Kline, 2015; Little, 2013). Model fit is assessed at each step, before proceeding to the next. First, a test of configural invariance establishes that the general pattern of the model fit in both groups. The next step is to test for metric invariance. In this step, constraints are added to hold the factor loadings, or paths between the latent factors and the items, to be equal across groups. Finally, a test of scalar invariance constrains the item intercepts to be consistent across groups and assesses whether the scale characteristics are consistent across the two groups. Once it is established that the measure fits relatively similarly across both groups, the hypothesis can be tested on the full structural model. The full structural model included directional arrows between the latent variables, and used the combined junior college and college sample. In this step, the latent psychological engagement, and the observed participation duration and frequency variables, predicted the overall latent PYD factor. Finally, to assess how the model fit across activity type (sports vs. non-sports, structured vs. unstructured), we conducted multiple-group SEM (Kline, 2015). 


\section{Psychological Engagement and PYD}

\section{Results}

Means, standard deviations, and correlations are presented in Table 1. Higher maternal education was related to greater activity frequency and duration in the junior college sample, and greater affective engagement in the college sample. Male participants reported significantly greater activity frequency, and older youth reported greater PYD, in the college sample only. Activity frequency and duration were positively and significantly correlated in both samples, and related to higher scores on the affective and relational/spiritual composites, but cognitive engagement was only related to greater duration in the junior college sample, and greater frequency in the college sample. Neither duration nor frequency were related to greater PYD. Cognitive, affective, and relational/spiritual engagement all were positively and significantly intercorrelated, in both samples. All three psychological engagement composites were positively related to PYD, in both samples.

For the main analysis, the model included the three psychological engagement composite variables (cognitive, affective, and relational/spiritual) loading onto a latent first-order psychological engagement factor and the five PYD composite variables (competence, character, caring, confidence, connections) loading onto a latent first-order PYD factor. To test for invariance across the college and junior college samples, we began with the measurement model, in which the two latent variables were correlated. We found full configural, metric, and scalar invariance (see Appendix for the results of these tests, and for the full measurement model). An examination of residuals during the test for configural invariance revealed a large standardized residual between the manifest confidence and connection variables. A correlation was added between error terms on the variables at that step.

To test our main hypotheses, we tested our structural model, with observed indicators of duration and frequency of participation and the psychological engagement latent variable predicting the latent overall PYD factor (see Figure 1$)$. The model fit well $(C F I=.978, R M S E A=$ $\left..040, \chi^{2}(30)=50.034, p=0.012\right)$. Consistent with past research (Ramey, Lawford, \& RoseKrasnor, 2016; Ramey, Lawford, \& Rose-Krasnor, 2017), the loadings on the latent psychological engagement factor were all similarly high (.71-.89), although affective engagement had the highest loading. Loadings of competence and confidence onto the PYD latent factor were low, consistent with past research (Geldhof et al., n.d.; Geldhof, Bowers et al., 2015). As predicted, psychological engagement significantly and moderately predicted PYD $(.41, p<.001)$. Unexpectedly, however, neither duration $(-.06, p=.363)$ nor frequency of participation $(-.09, p=.117)$ significantly predicted PYD over and above psychological 
Table 1. Summary of Means, Standard Deviations, and Zero-Order Correlations

\begin{tabular}{|c|c|c|c|c|c|c|c|c|c|c|c|}
\hline \multirow[b]{2}{*}{ Measure } & \multirow{2}{*}{$\begin{array}{l}\text { Sample } 1 \\
M(S D)\end{array}$} & \multirow{2}{*}{$\begin{array}{l}\text { Sample } 2 \\
M(S D)\end{array}$} & \multirow[b]{2}{*}{1} & \multirow[b]{2}{*}{2} & \multirow[b]{2}{*}{3} & \multirow[b]{2}{*}{4} & \multirow[b]{2}{*}{5} & \multirow[b]{2}{*}{6} & \multirow[b]{2}{*}{7} & \multirow[b]{2}{*}{8} & \multirow[b]{2}{*}{9} \\
\hline & & & & & & & & & & & \\
\hline 1. Age & $18.69(1.36)$ & $20.49(2.11)$ & & .02 & -.02 & -.09 & -.03 & .05 & -.06 & .03 & $.20 *$ \\
\hline 2. Gender & $67.7 \%$ female & $68.8 \%$ female & .04 & & .08 & $.23 * *$ & -.02 & .06 & .11 & .09 & -.14 \\
\hline 3. Maternal education & $3.32(1.21)$ & $2.98(1.21)$ & -.12 & -.08 & & .01 & .02 & .13 & $.19 *$ & .10 & .07 \\
\hline 4. Frequency & $5.25(1.21)$ & $4.89(1.46)$ & -.02 & -.05 & $.21 * *$ & & $.32 * *$ & $.20 * *$ & $.27 * *$ & $.17 *$ & -.03 \\
\hline 5. Duration & $4.82(1.43)$ & $4.35(1.73)$ & -.01 & -.11 & $.15^{*}$ & $.28 * *$ & & .12 & $.36 * *$ & $.30 * *$ & .00 \\
\hline 6. Cognitive & $3.82(0.82)$ & $3.75(0.92)$ & .03 & -.03 & -.01 & .12 & $.13^{*}$ & & $.64 * *$ & $.55^{* *}$ & $.33 * *$ \\
\hline 7. Affective & $4.01(0.83)$ & $3.96(0.89)$ & .07 & -.12 & -.01 & $.23 * *$ & $.31 * *$ & $.63 * *$ & & $.66 * *$ & $.31 * *$ \\
\hline 8. Relational/Spiritual & $3.94(0.86)$ & $3.98(0.87)$ & .00 & -.02 & -.02 & $.14 *$ & $.29 * *$ & $.58 * *$ & $.71 * *$ & & $.32 * *$ \\
\hline 9. PYD & $3.86(0.46)$ & $3.70(0.51)$ & .07 & -.10 & -.06 & -.03 & .06 & $.13 *$ & $.17^{* *}$ & $.23 * *$ & \\
\hline
\end{tabular}

Note: Values for Sample 1 (junior college) are below the diagonal, and values for Sample 2 (college) are above the diagonal. Gender was coded as 1 (female) and 2 (male). Positive Youth Development (PYD). $* p<.05, * * p<.01$. 
Psychological Engagement and PYD

Figure 1. SEM Model of Psychological Engagement and Behavioral Participation Predicting Positive Youth Development

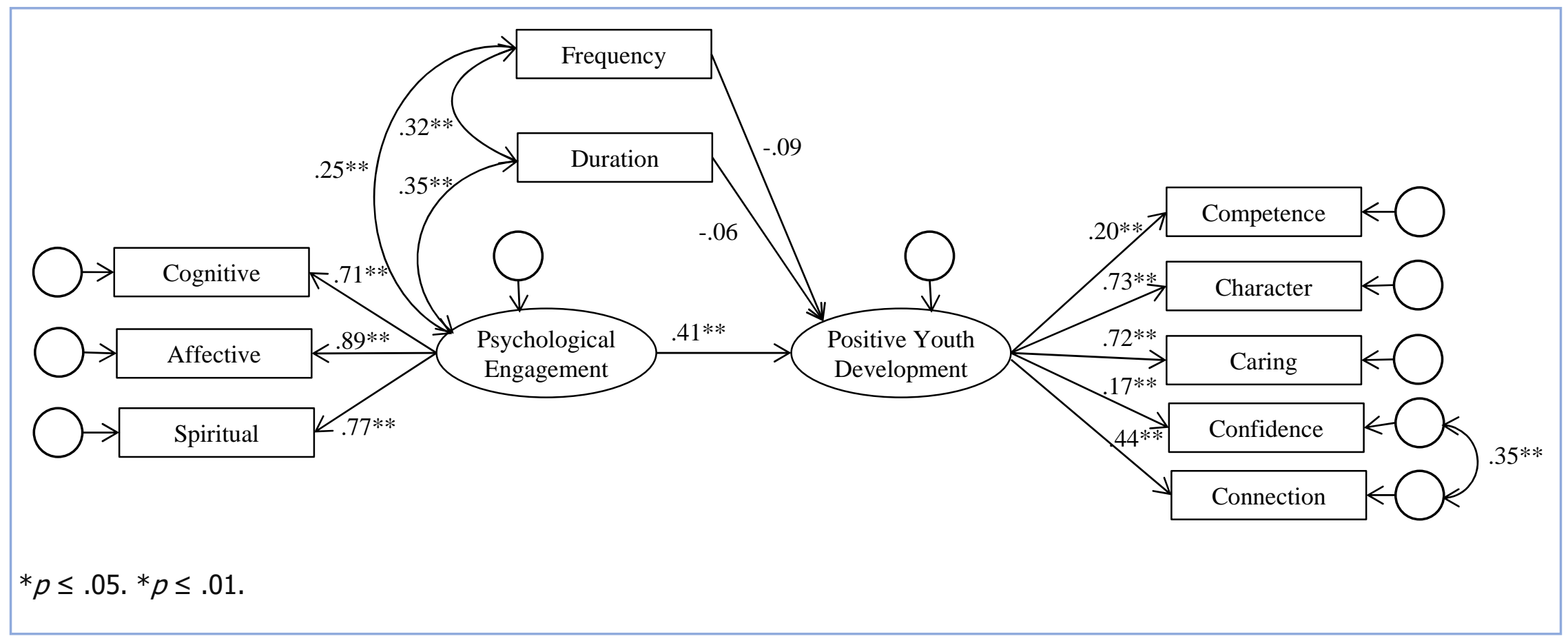




\section{Psychological Engagement and PYD}

engagement. Given this finding, we tested for moderation between psychological engagement and frequency and duration of participation. This test could assess the possibility that, for example, high participation in highly psychologically-engaging activities would be especially advantageous in predicting PYD. We first imputed factor scores for the latent psychological engagement variable. We then computed interaction terms between psychological engagement and both duration and frequency. The model was saturated, so no model fit indices are presented. The interaction terms did not significantly predict PYD (frequency $\times$ psychological engagement, .016, $p=.717$; duration $\times$ psychological engagement, $-.014, p=.763$ ).

To assess whether there were differences in the model across activity type, we conducted two additional multiple-group SEM analyses (Kline, 2015). First, as with the preliminary analysis on the college and junior college samples, we tested for invariance for both structured and unstructured, and sports and non-sports activity types. We found full configural, metric, and scalar invariance in both sets of analyses (see Appendix). We then tested the invariance of the structural model, or construct-level invariance (Cheung \& Rensvold, 2002). This assessed whether the hypothesized associations were similar across sport and non-sport activities, as well as structured and unstructured activities. We tested for equality of structural coefficients, constraining all structural paths (i.e., the factor loadings, and the regression paths from the psychological engagement latent variable, and participation frequency and duration, to PYD) to be equal in both groups. The model did not differ by sport and non-sport activity type, $\chi^{2}(10)=$ $16.111, p=.096$. The difference between the CFI values on the constrained and unconstrained models was below the recommended cutoff criterion of 0.01 ( $\triangle C F I=0.007$; Byrne, 2016). The model also did not differ across structured and unstructured activity type, $\chi^{2}(10)=15.174, p=$ .126). The difference between the $C F I$ values on the constrained and unconstrained models was below the recommended cutoff criterion of $0.01(\triangle C F I=0.006$; Byrne, 2016; Cheung \& Rensvold, 2002).

Although the relation between psychological engagement and PYD did not differ as a function of activity type, psychological engagement was slightly higher in the structured activities ( $M=$ $3.968, S D=0.705)$ than in unstructured activities $(M=3.754, S D=0.831), t(419)=-2.631$, $p=.009, d=-.289$. We found no meaningful difference between sports $(M=3.970, S D=$ $0.661)$ and non-sports $(M=3.862, S D=0.808), t(419)=-1.487, p=.138, d=-.146$. 


\section{Psychological Engagement and PYD}

\section{Discussion}

We assessed a model of psychological engagement and behavioral participation, as predictors of PYD, in samples in late adolescence and emerging adulthood. In the first known study to include both behavioral participation and multidimensional psychological engagement in predicting the Five CS of PYD, we found that youth with greater psychological engagement also had higher PYD. This finding was consistent across samples and across different types of activities. The frequency and duration of young people's participation, however, were not related to PYD.

As suggested by PYD frameworks (Geldhof, Bowers et al., 2015), PYD requires settings that fit with youth's strengths and needs. Our findings suggest that psychological engagement in an activity or program might be an important indicator of this fit and of the suitability of developmental opportunities for individual youth. In line with past studies of psychological engagement, cognitive, affective, and relational engagement were all important aspects of psychological engagement. This might indicate that it is not any one element or aspect of psychological engagement (e. g., enjoying the activity) that is important, and that program leaders who are interested in psychological engagement and PYD should be attentive to the different aspects of youth's engagement. In programs, then, practitioners and researchers should be looking for ways that activities can be not only fun, but also have opportunities for other aspects of psychological engagement, such as concentration and connections to others.

Our findings suggest that psychological engagement was an important measure of the process occurring in programs and other settings, as it pertains to PYD as a potential outcome of youth programs and other activity settings (Geldhof, Bowers et al., 2015). Thus, it should be considered in evaluating developmental contexts, including youth programs. Programs seeking to promote PYD among older adolescents and emerging adults may benefit from tracking and evaluating youth's psychological engagement in the program.

Unexpectedly, behavioral participation was not related to PYD. Past research has found unique links between duration and frequency and developmental indicators (Akiva, Cortina, Eccles, Smith, 2013; Denault \& Poulin, 2017; Viau et al., 2015). Although we hypothesized that the roles of these behavioral indicators might be less powerful than psychological engagement, we expected both would significantly predict PYD. Behavioral participation might be related to some specific aspects of PYD, found in past literature (e.g., Adachi \& Willoughby, 2014), even if it was not related to a global PYD measure in the current analysis. 


\section{Psychological Engagement and PYD}

Structured activities and programs were more engaging for participants in the current study than were unstructured contexts, reinforcing the notion that they are an important setting for PYD. Nevertheless, links between psychological engagement and PYD held across sport and non-sport and structured and unstructured activities. These findings suggest that not only was psychological engagement an important predictor of PYD, but it was so regardless of the activity type. These findings were in line with past research that has failed to find consistent, systematic differences in the benefits of sports or non-sport activities (Agans et al., 2014; Forneris et al., 2014; Vandell et al., 2015). It also adds to research by Larson and colleagues (e.g., Larson et al., 2006) examining structured and unstructured activity types and youth development. These prior findings suggest program type might not be best way to determine the type of developmental experiences young people are likely to have in an activity (see also Gadbois et al., 2019; Hansen et al., 2010; Rose-Krasnor, 2009).

\section{Limitations and Future Research}

The current study had a number of limitations. The data were cross-sectional and therefore we cannot make conclusions about the direction of the associations. Psychological engagement may contribute to greater PYD, but youth with more positive functioning also may become more psychologically engaged in their activities. A further limitation is our focus on a single activity for each participant. Breadth, or participation in a range of different activity types, has been linked to greater well-being in late adolescence and emerging adulthood (Busseri et al., 2011). Similarly, Zarrett et al. (2009) found that participation patterns were important in predicting PYD. Thus, it appears that a more complex analysis based on participation profiles is relevant for the promotion of PYD and should receive more consideration in future research. Finally, this study relied on convenience samples of older adolescents and emerging adults. More research is needed to replicate these findings in younger youth and broader ages of potential program participants, as well as those outside of post-secondary institutions.

\section{Implications}

Despite limitations, our findings have implications for youth programs and program leaders. In a study of youth-serving organizations, Green and Davis (2015) found that organizational staff both recognized the importance of PYD, and were seeking ways to strengthen youth's capacity for PYD. Our findings suggest that psychological engagement might be an important way for practitioners to promote PYD. In conjunction with our findings, practitioners might also do well 


\section{Psychological Engagement and PYD}

to consider recent research on program practices that promote psychological engagement in programs. Past research has suggested that key program aspects, such as positive relationships among peers and with program leaders, and involvement in outdoor activities, were linked to greater engagement (Champine \& Johnson, 2017). Other program features that may promote psychological engagement include opportunities to learn and develop new skills, feeling included by group members, and having the right amount of program structure (Ramey et al., 2015). A study by Burrow, Agans, and Rainone (2018) suggested that incorporating exercises in which youth write about their own sense of purpose in life may lead to increases in youth psychological engagement in programs. Prior studies of ways to promote psychological engagement have focused broadly on the adolescent years. However, such strategies may be more important for older adolescents, who may experience declines in engagement with age (Burrow et al., 2018).

Finally, our research suggests that the scope of psychological engagement reaches beyond structured to unstructured activities. Although participants reported that structured activities tended to be more psychologically engaging than unstructured activities, these differences were moderate, and engagement in unstructured activities also predicted greater PYD. These findings suggest that program leaders and other adults should consider promoting youth's psychological engagement both within their structured programs and within less structured settings. This might mean encouraging young people to explore unstructured activities (e.g., reading, cooking) that young people find psychologically engaging. These activities may involve not just enjoyment, but other elements of engagement, such as focus, learning, and connection to others.

\section{Conclusions}

In the context of large bodies of literature regarding both the positive role of program and activity participation (Vandell et al., 2015) and PYD (e.g., Lerner et al., 2015), the current study was unique in testing youth's overall psychological engagement, as well as behavioral participation, in activities as predictors of overall PYD. It was also unique in pointing to the relative importance of psychological engagement in predicting overall PYD, across two independent samples and different activity types. Thus, the current study makes a significant contribution to the literature, pointing to the need for greater focus on psychological engagement in youth development programs and other activities. 
Journal of Youth Development | http://jyd.pitt.edu/ | Vol. 14 Issue 3 DOI 10.5195/jyd.2019.769

\section{Psychological Engagement and PYD}

\section{References}

Adachi, P., \& Willoughby, T. (2014). It's not how much you play, but how much you enjoy the game: the longitudinal associations between adolescents' self- esteem and the frequency versus enjoyment of involvement in sports. Journal of Youth and Adolescence, 43(1), 137-145. doi:10.1007/s10964-013-9988-3

Agans, J. P., Champine, R. B., De Souza, L. M., Mueller, M. K., Johnson, S. K., \& Lerner, R. M. (2014). Activity involvement as an ecological asset: Profiles of participation and youth outcomes. Journal of Youth and Adolescence, 43 (6), 919-932. doi:10.1007/s10964-014-0091-1

Agans, J. P., \& Geldhof, G. J. (2012). Trajectories of participation in athletics and positive youth development: The influence of sport type. Applied Developmental Science, 16(3), 151-165. doi:10.1080/10888691.2012.697792

Akiva, T., Cortina, K. S., Eccles, J. S., Smith, S. (2013). Youth belonging and cognitive engagement in organized activities: A large-scale field study. Journal of Applied Developmental Psychology, 34(5), 208-218. doi:10.1016/j.appdev.2013.05.001

Arnold, M. E., \& Silliman, B. (2017). From theory to practice: A critical review of positive youth development program frameworks. Journal of Youth Development, 12(2), 1-20. doi:10.5195/jyd.2017.17

Bohnert, A., Fredricks, J., \& Randall, E. (2010). Capturing unique dimensions of youth organized activity involvement: Theoretical and methodological considerations. Review of Educational Research, 80(4), 576-610. doi:10.3102/0034654310364533

Burrow, A. L., Agans, J. P., \& Rainone, N. (2018). Exploring purpose as a resource for promoting youth program engagement. Journal of Youth Development, 13(4). doi:10.5195/jyd.2018.601

Busseri, M. A., Rose-Krasnor, L., Pancer, S. M., Pratt, M. W., Adams, G. R., Birnie-Lefcovitch, S., . . \& Wintre, M. G. (2011). A longitudinal study of breadth and intensity of activity involvement and the transition to university. Journal of Research on Adolescence, 21(2), 512-518.

Busseri, M. A., Rose-Krasnor, L., \& Centre of Excellence for Youth Engagement. (2009). The engagement portrait: A snapshot of your involvement (Unpublished survey). Available at https://archives.studentscommission.ca/yap/resources/CEYE_PortraitSurvey_e.pdf

Byrne, B. M. (2016). Structural equation modeling with Amos: Basic concepts, applications, and programming ( $3^{\text {rd }}$ ed.) New York, NY: Taylor \& Francis.

Champine, R. B., Johnson, S. K. (2017). Towards the promotion of positive development among boys in challenging contexts: A mixed-methods study of engagement in the Scoutreach Initiative. Journal of Youth Development, 12(4). doi:10.5195/jyd.2017.521

Cheung, G. W., \& Rensvold, R. B. (2002). Evaluating goodness-of-fit indexes for testing measurement invariance. Structural Equation Modeling, 9(2), 233-255. 
Journal of Youth Development | http://jyd.pitt.edu/ | Vol. 14 Issue 3 DOI 10.5195/jyd.2019.769

\section{Psychological Engagement and PYD}

Csikszentmihalyi, M. (1999). If we are so rich, why aren't we happy? American Psychologist, 54(10), 821827.

Denault, A.-S., \& Poulin, F. (2016). What adolescents experience in organized activities: Profiles of individual and social experiences. Journal of Applied Developmental Psychology, 42, 40-48. doi:10.1016/j.appdev.2015.11.004

Denault, A.-S., \& Poulin, F. (2017). Trajectories of participation in organized activities and outcomes in young adulthood. Applied Developmental Science. Advance online publication. doi:10.1080/10888691.2017.1308829

Erentaitè, R., \& Raižienè, S. (2015). Lithuanian version of measure of positive youth development based on the Five Cs model. European Journal of Developmental Psychology, 12, 701-717. doi:10.1080/17405629.2015.1091772

Forgeard, M. J. C., \& Benson, L. (2017). Extracurricular involvement and psychological adjustment in the transition from adolescence to emerging adulthood: The role of mastery and creative selfefficacy. Applied Developmental Science, 23(1). Advance online publication. doi:10.1080/10888691.2017.1288124

Forneris, T., Camiré, M., \& Williamson, R. (2014). Extracurricular activity participation and the acquisition of developmental assets: Differences between involved and noninvolved Canadian high school students. Applied Developmental Science, 19(1), 47-55. doi:10.1080/10888691.2014.980580

Gadbois, S., Bowker, A., Rose-Krasnor., L., \& Findlay, L. (2019). A qualitative examination of psychologically engaging sport, nonsport, and unstructured activities. The Sport Psychologist, 33(2), 97-109. doi:10.1123/tsp.2018-0032

Geldhof, G. J., Bowers, E. P., Boyd, M. J., Mueller, M. K., Napolitano, C. M., Schmid, K. L., . . Lerner, R. M. (2014). Creation of short and very short measures of the 5 Cs of PYD. Journal of Research on Adolescence, 24(1), 163-176. doi:10.1111/jora.12039

Geldhof, G. J., Bowers, E. P., Boyd, M. J., Mueller, M. K., Napolitano, C. M., Schmid, K. L., . . Lerner, R. M. (n.d.). The creation and validation of short and very short measures of PYD. Retrieved from http://www.thrivefoundation.org/thriving

Geldhof, G. J., Bowers, E. P., Mueller, M. K., Napolitano, C. M., Callina, K. S., Walsh, K. J., . . . Lerner, R. M. (2015). Chapter 9. The Five Cs model of positive youth development. In E. P. Bowers, G. J. Geldhof, S. K. Johnson, L. Hilliard, R. M Hershberg, J. V. Lerner, \& R. M. Lerner (Eds.), Promoting positive youth development: Lessons from the 4-H study. In the Series Advancing Responsible Adolescent Development (pp. 161-186). Springer. doi:10.1007/978-3-319-17166-1_9

Geldhof, G. J., Gestsdottir, S., Stefansson, K., Johnson, S. K., Bowers, E. P., \& Lerner, R. M. (2015). Selection, optimization, and compensation: The structure, reliability, and validity of forced-choice versus likert-type measures in a sample of late adolescents. International Journal of Behavioral Development, 39(2), 171-185. doi:10.1177/0165025414560447 
Journal of Youth Development | http://jyd.pitt.edu/ | Vol. 14 Issue 3 DOI 10.5195/jyd.2019.769

\section{Psychological Engagement and PYD}

Green, J. W., \& Davis, J. M. (2015). PYD and professional development of youth organizations. Journal of Youth Development, 10(1).

Hansen, D. M., Larson, R. W., \& Dworkin, J. B. (2003). What adolescents learn in organized youth activities: A survey of self-reported developmental experiences. Journal of Research on Adolescence, 13(1), 25-55.

Hansen, D. M., Skorupski, W. P., Arrington, T. L. (2010). Differences in developmental experiences for commonly used categories of organized youth activities. Journal of Applied Developmental Psychology, 31(6), 413-421. doi:10.1016/j.appdev.2010.07.001

Holt, N. (Ed). (2016). Positive youth development through sport ( $2^{\text {nd }}$ ed.). Taylor \& Francis.

Hunter, J. P., \& Csikszentmihalyi, M. (2003). The positive psychology of interested adolescents. Journal of Youth and Adolescence, 32(1), 27-35.

Kline, R. B. (2015). Principles and practice of structural equation modeling (4th ed.). New York, NY: Guilford Press.

Larson, R. W. (2000). Toward a psychology of positive youth development. American Psychologist, 55(1), 170-183. doi:10.1037//0003-066X.55.1.170

Larson, R. W., Hansen, D. M., \& Moneta, G. (2006). Differing profiles of developmental experiences across types of organized youth activities. Developmental Psychology, 42(5), 849863. doi:10.1037/0012-1649.42.5.849

Lerner, R. M. (2018). Character development among youth: Linking lives in time and place. International Journal of Behavioral Development, 42(2), 267-277. doi:10.1177/0165025417711057

Lerner, R. M., Lerner, J. V., Bowers, P. E., \& Geldhof, G. J. (2015). Positive youth development and relational-developmental-systems. In R. M. Lerner (Ed.), Handbook of child psychology and developmental science ( $7^{\text {th }}$ ed., Vol. 1, pp. 607-651). New York, NY: Wiley.

Little, T. D. (2013). Longitudinal structural equation modeling. New York, NY: Guilford.

Mahoney, J. L., Stattin, H., \& Lord, H. (2004). Unstructured youth recreation center participation and antisocial behaviour development: Selection influences and the moderating role of antisocial peers. International Journal of Behavioral Development, 28(6), 553-560. doi:10.1080/01650250444000270

McGuire, J. K., \& Gamble, W. C. (2006). Community service for youth: the value of psychological engagement over number of hours spent. Journal of Adolescence, 29(2), 289-298. doi:10.1016/j.adolescence.2005.07.006

Mueller, M. K., Phelps, E., Bowers, E. P., Agans, J. P., Urban, J. B., \& Lerner, R. M. (2011). Youth development program participation and intentional self-regulation skills: Contextual and individual bases of pathways to positive youth development. Journal of Adolescence, 34(6), 1115-1126.

Pancer, S. M., Rose-Krasnor, L., \& Loiselle, L. (2002). Youth conferences as a context for engagement. In B. Kirshner, J. L. O'Donoghue, \& M. McLaughlin (Eds.), Youth participation: Improving institutions 
Journal of Youth Development | http://jyd.pitt.edu/ | Vol. 14 Issue 3 DOI 10.5195/jyd.2019.769

\section{Psychological Engagement and PYD}

and communities. New directions for youth development, 96, 47-64. San Francisco, CA: JosseyBass. doi:10.1002/yd.26

Ramey, H. L., Busseri, M. A., Khanna, N., Youth Net Hamilton, Youth Net/Réseau Ado Ottawa, \& RoseKrasnor, L. (2010). Youth engagement and suicide risk: Testing a mediated model in a Canadian community sample. Journal of Youth and Adolescence, 39(3), 243-258.

Ramey, H. L., Lawford, H. L., \& Rose-Krasnor, L. (2016). Motivations for participation and psychological engagement in emerging adults' leisure activities. Leisure Sciences, 38(4), 338-356. doi:10.1080/01490400.2015.1095661

Ramey, H. L., Lawford, H. L., \& Rose-Krasnor, L. (2017). Doing for others: Youth's contributing behaviors and psychological engagement in youth-adult partnerships. Journal of Adolescence, 55, 129-138. doi:10.1016/j.adolescence.2017.01.001

Ramey, H. L., Rose-Krasnor, L., \& Lawford, H. L. (2017). Youth-adult partnerships and youth identity style. Journal of Youth and Adolescence, 46(2), 442-453. doi:10.1007/s10964-016-0474-6

Ramey, H. L., Rose-Krasnor, L., Busseri, M. A., Gadbois, S., Bowker, A., \& Findlay, L. (2015). Measuring psychological engagement in youth activity involvement. Journal of Adolescence, 45, 237-249. doi:10.1016/j.adolescence.2015.09.006

Rose-Krasnor, L. (2009). Future directions in youth involvement research. Social Development, 18(2), 497-509. doi:10.1111/j.1467-9507.2008.00506.x

Scales, P. C., Benson, P. L., Oesterle, S., Hill, K. G., Hawkins, J. D., \& Pashak, T. J. (2016). The dimensions of successful young adult development: A conceptual and measurement framework. Applied Developmental Science, 20(3), 150-174. doi:10.1080/10888691.2015.1082429

Schafer, J. L., \& Graham, J. W. (2002). Missing data: our view of the state of the art. Psychological Methods, 72 , 147-177. doi:10.1037/1082-989X.7.2.147

Vandell, D. L., Larson, R. W., Mahoney, J. L., \& Watts, T. W. (2015). Children's organized activities. In M. H. Bornstein \& T. Leventhal (Eds.) (Editor-in-Chief: R. M. Lerner), Handbook of child psychology and developmental science. Vol. 4: Ecological settings and processes in developmental systems (7th ed., pp. 305-344). Hoboken, N.J.: Wiley.

Viau, A., Denault, A.-S., \& Poulin, F. (2015). Organized activities during high school and adjustment one year post high school: Identifying social mediators. Journal of Youth and Adolescence, 44(8), 1638-1651. doi:10.1007/s10964-014-0225-5

Zarrett, N., Fay, K., Li, Y., Carrano, J., Phelps, E.., \& Lerner, R. (2009). More than child's play: Variableand pattern-centered approaches for examining the effects of sport participation on youth development. Developmental Psychology, 45(2), 368-382. doi:10.1037/a0014577 


\section{Psychological Engagement and PYD}

\section{Appendix}

\section{Invariance Testing}

\section{Invariance Testing Across Samples}

To test for invariance across the two samples (Sample 1-junior college and Sample 2-college), we began with the measurement model, in which the two latent variables were correlated. We assessed configural invariance. This model had good fit $\left(C F I=.951, R M S E A=.050, \chi^{2}(38)=\right.$ 78.556, $p<.001$ ), however, an examination of residuals revealed a large standardized residual between the manifest confidence and connection variables. A correlation was added between the error terms on these variables, resulting in an improved fit $\left(\Delta C F I=.049, \Delta \chi^{2}(2)=42.778\right.$, $p<.001)$. Next, we tested metric invariance across samples. We constrained the factor loadings across the groups to be equal. The difference between the CFI values on the constrained and unconstrained models was below the recommended cutoff criterion of 0.01 $\left(\Delta C F I=0.007, \Delta \chi^{2}(8)=13.809, p=.087\right.$; Byrne, 2016; Cheung \& Rensvold, 2002). This indicated that the metric model did not differ across samples. Finally, we tested for and found full scalar invariance, with the difference between the CFI values on the constrained and unconstrained models below the recommended cutoff criterion, $\Delta C F I=0, \Delta \chi^{2}(9)=14.875, p=$ .094; see Figure A1 for the full measurement model).

\section{Invariance Testing Across Structured and Non-Structured Activity Types}

To test for invariance across structured and non-structured groups, we again began with the measurement model, in which the two latent variables were correlated. We assessed configural invariance. This model had good fit $\left(C F I=.975, R M S E A=.037, \chi^{2}(36)=56.843, p=.015\right)$. Next, we tested metric invariance across structured and unstructured activity types. We constrained the factor loadings across the groups to be equal. The difference between the CFI values on the constrained and unconstrained models was below the recommended cutoff criterion of $0.01\left(\Delta C F I=0.002, \Delta \chi^{2}(8)=9.274, p=.320\right.$; Byrne, 2016; Cheung \& Rensvold, 2002). This indicated that the metric model did not differ across activity type. Finally, we tested for and found full scalar invariance. Although the $\chi^{2}$ difference between the constrained and unconstrained models was significant $\left(\Delta \chi^{2}(1)=5.078, p=.024\right)$, the difference between the $C F I$ values on two models was still below the recommended cutoff criterion of 0.01 ( $\triangle C F I=$ 0.007; Byrne, 2016; Cheung \& Rensvold, 2002). 
Figure A1. Measurement Model of Psychological Engagement and Positive Youth Development.

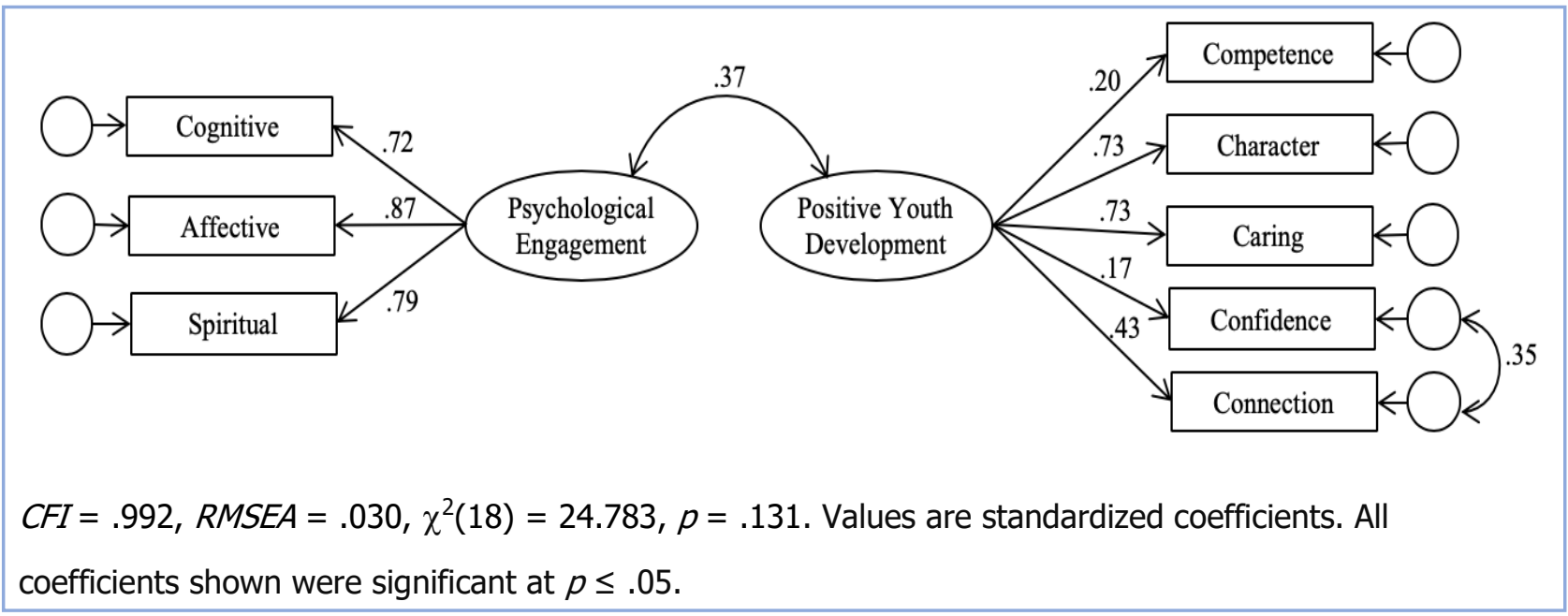

\section{Invariance Testing Across Sports and Non-Sports Activity Types}

To test for invariance across sports and non-sports group, we again began with the measurement model. We assessed configural invariance. This model had good fit ( $C F I=.986$, RMSEA $\left.=.028, \chi^{2}(36)=47.658, p=.093\right)$. Next, we tested metric invariance across sports and non-sports activity types. The difference between the CFI values on the constrained and unconstrained models was below the recommended cutoff criterion $\left(\triangle C F I=0.003, \Delta \chi^{2}(8)=\right.$ $9.830, p=.277)$. This indicated that the metric model did not differ across activity type. Finally, we tested for and found full scalar invariance, with the difference between the CFI values on the constrained and unconstrained models below the recommended cutoff criterion, $\triangle C F I=$ $\left..002, \Delta \chi^{2}(1)=3.207, p=.073\right)$. 